\title{
Retinoic Acid Combined with Vitamin A Synergizes to Increase Retinyl Ester Storage in the Lungs of Newborn and Dexamethasone-Treated Neonatal Rats
}

\author{
A. Catharine Ross ${ }^{a}$ Namasivayam Ambalavanan ${ }^{b}$ \\ ${ }^{a}$ Department of Nutritional Sciences and Huck Institute for Life Sciences, Pennsylvania State University, \\ University Park, Pa., and ${ }^{\mathrm{b}}$ Division of Neonatology, Department of Pediatrics, University of Alabama at Birmingham, \\ Birmingham, Ala., USA
}

\section{Key Words}

Lung maturation - Glucocorticoids - Lung morphometry •

Vitamin A status · Retinyl ester storage, liver $\cdot$ Retinoic acid

\begin{abstract}
Background: Retinyl esters (REs), the major storage form of vitamin A (retinol), provide substrates for the production of bioactive retinoids, including retinoic acid (RA), which are known to promote lung development and maturation. We previously showed that the nutrient-metabolite combination VARA (molar ratio 10 vitamin A to 1 RA), synergistically increased REs in the lungs of 1-week-old rats, compared to vitamin A or RA alone. Objectives: To test the hypotheses, first, that VARA is more effective in increasing lung RE than is vitamin $A$ in newborn rats prior to alveolarization, and, second, that the effect of VARA is maintained during concurrent treatment with the glucocorticoid, dexamethasone (Dex). Methods: Newborn rats were treated with VARA, vitamin A alone, or oil (C) on postnatal days (P) 1-3, and RE in the lungs was quantified on $\mathrm{P} 4$, and again on $\mathrm{P} 8$ to assess retention. Additionally, neonatal rats were treated on P5-7 with VARA with and without Dex, and the lung and liver REs were quantified on P8. Results and Conclusions: Lung RE was nearly 8-fold higher in VARA compared to vitamin A-treated rats on
\end{abstract}

P4 $(p<0.01)$ and 2.5 -fold higher on P8. In neonates co-treated with Dex and VARA on P5-7, the elevation in lung RE on P8 by VARA was not antagonized by Dex, although Dex reduced growth. Lung morphology and development were not significantly altered. The VARA combination may significantly increase lung $\mathrm{RE}$ content even during concurrent $\mathrm{Dex}$ therapy. Because lung retinoids are important for lung maturation and repair, increasing lung RE may possibly have clinical benefit.

Copyright $\odot 2007$ S. Karger AG, Basel

\section{Introduction}

Bronchopulmonary dysplasia (BPD) is a common cause of morbidity and a risk factor for poor long-term outcome in extremely premature infants [1-3]. Several studies have shown that vitamin A can reduce the risk of BPD in premature infants [2, 4-7]. In animal models, vitamin A deficiency is associated with histopathological changes similar to those in BPD [8]. Conversely, retinol has been shown to promote elastin formation [9] and alveolar development [10]. A beneficial effect of vitamin A on lung maturation is plausible because the active metabolite and hormonal form of vitamin A, retinoic acid

\section{KARGER}

(C) 2007 S. Karger AG, Basel

Fax +41613061234

E-Mail karger@karger.ch

www.karger.com
Accessible online at:

www.karger.com/neo
Dr. A. Catharine Ross

Department of Nutritional Sciences and Huck Institute for Life Sciences

126-S Henderson Building, Pennsylvania State University

University Park, PA 16802 (USA)

Tel. +1 814865 4721, Fax +1 814865 4723, E-Mail acr6@psu.edu 
(RA), is well known to be an important regulator of cell proliferation, cell differentiation, and cell-cell interactions in nearly all tissues $[11,12]$. In the embryonic period, retinoids are essential for normal stromal cell-mesenchymal cell interactions and organogenesis [13-15], while in the postnatal period retinoids are important regulators of lung growth, alveolar septation, and elastin formation $[9,10,14,16-21]$.

Retinyl esters (REs), the major storage form of vitamin A in most tissues, are important for maintaining retinoid homeostasis because the retinol released by the hydrolysis of REs can be metabolized in several ways depending on the vitamin A status, resulting in the re-esterification of retinol, its release into plasma, or its conversion into retinal and $\mathrm{RA}$, the two major functional metabolites of vitamin $A[22,23]$. Reserves of vitamin $A$ in the liver, as well as plasma retinol levels, are relatively low at birth and lower still in prematurely born infants $[2,5,24-26]$. In the rat, the concentration of RE in the lungs peaks around gestational day 18 (E18), then decreases progressively until the third postnatal day (P3) [27]. Although lung and liver REs were higher in the offspring of mothers supplemented with vitamin A during late pregnancy, the concentration of REs in the lungs still declined after birth [28].

In a previous study in neonatal rats, we showed that a nutrient-metabolite combination containing vitamin A and RA in a 10:1 molar ratio (VARA) was several times more effective than vitamin A alone in increasing the concentration of REs in the lungs, as determined in P5P8 neonates given a daily oral dose of VARA or the same amounts of its individual components [29]. Interestingly, the synergistic effect of VARA on RE formation was selective for the lungs, as VARA and the same amount of vitamin A alone increased liver REs to the same extent. In a follow-up study, we found that a greater fraction of newly absorbed ${ }^{3} \mathrm{H}$-retinol was taken into the lungs of neonates when ${ }^{3} \mathrm{H}$-retinol was co-administered with VARA versus with vitamin A alone, showing that a small proportion of RA included with vitamin A can have a significant impact on the metabolism of retinol in the lungs.

It is possible that the ability of VARA to enhance retinol uptake and RE storage in the lungs depends on the stage of lung development, and/or that it could be modified by other agents given concurrently. At birth, the lungs of newborn rats and mice are still in the saccular stage. Lung RE content declines during the saccular stage [26], which occurs between 24 and 38 weeks' gestation in humans and between E17.5 to P4 in mice [30]. Glucocor- ticoids continue to be used in neonates for the treatment of BPD despite knowledge of their adverse effects [31,32]. Previous studies have shown that dexamethasone (Dex) may reduce the levels of retinoid-binding proteins [33] and receptors [34], which potentially could affect the metabolism of retinol and the formation of REs. Thus, in the present studies we have addressed two questions: (1) is VARA more effective than vitamin A alone in increasing the lung RE concentration in the period prior to the onset of alveolarization, and (2) does Dex antagonize the ability of VARA to promote RE storage in the lungs of neonates?

\section{Methods}

\section{Oral Doses}

Vitamin A, VARA and oil (control) were prepared for oral administration as described previously [29]. Briefly, all-trans-retinyl palmitate and all-trans-RA (Sigma-Aldrich, St. Louis, Mo., USA) were prepared in canola oil as $2 \times$ concentrates, then mixed 1:1 (wt:wt) with each other to form the VARA dose, which had a molar ratio of about 10 vitamin A:1 RA ( $0.05 \mathrm{mmol}$ retinyl palmitate and $0.005 \mathrm{mmol} \mathrm{RA} / \mathrm{g}$ dose). As described previously [29], the dose of vitamin A for rats was similar, after adjustment for metabolic weight, to 50,000 IU of vitamin A (equal to $15 \mathrm{mg}$ retinol) that has been administered to human infants $[35,36]$, while the dose of RA was similar to a dose that promoted lung septation in neonatal rats [37]. Pups received approximately $0.4 \mu \mathrm{l} / \mathrm{g}$ body weight. Each pup was weighed daily before dosing and the dose volume was adjusted. Retinoids were stored at $4^{\circ} \mathrm{C}$ in foil-wrapped vials. Dex (Sigma-Aldrich) was prepared as a $0.5 \mathrm{mg} / \mathrm{ml}$ stock solution in ethanol and diluted 1:2,000 with sterile saline before administration [38].

Animals and Experimental Treatments

Animal procedures were approved by the Institutional Animal Use and Care Committee of the Pennsylvania State University. Pregnant Sprague-Dawley rats were bred in our animal facility and fed a vitamin A-adequate purified diet [39]. Food and water were freely available. In the first study, the time of birth was monitored and rat pups less than $24 \mathrm{~h}$ old (day $1=<24 \mathrm{~h}$ of birth) were randomized within 4 litters and treated on days P1, P2, and P3 with VARA or oil (control) only. VARA, vitamin A or oil was delivered directly into the neonate's mouth with a small-tipped micropipette. Tissues were collected from half of the neonates on $\mathrm{P} 4$ and from the remaining half on $\mathrm{P} 8$, without intervening treatment. In the second experiment designed to test the effect of VARA during co-treatment with Dex, pups were randomly assigned within litters to receive oil (control); VARA, Dex only, and Dex plus VARA on P5, P6 and P7. The dose used provided a neonate weighing $12.5 \mathrm{~g}$ with approximately $130 \mu \mathrm{g}$ of retinyl palmitate $(72 \mu \mathrm{g}$ or $0.25 \mu \mathrm{mol}$ retinol $)$ and $7.5 \mu \mathrm{g}(0.025 \mu \mathrm{mol})$ of RA, in about $5 \mu$ l of oily suspension. Neonates assigned to Dex treatment received $0.25 \mu \mathrm{g}$ Dex s.c. in $10 \mu \mathrm{l}$ of sterile saline, injected by microsyringe under the skin just above the tail each day, as described earlier by Massaro and Massaro [38]. 
At the end of each experiment, neonates were euthanized one at a time using carbon dioxide inhalation and weighed, and blood was collected for separation of plasma by centrifugation. The lungs and liver were removed, blotted, weighed and snap-frozen in liquid nitrogen for storage at $-80^{\circ} \mathrm{C}$ prior to retinoid analysis.

In order to determine changes in lung morphology, the experiment was repeated and the lungs of neonates treated with oil (control); VARA, Dex only, and Dex plus VARA on P5-P7 were perfused on P14 with phosphate-buffered $10 \%$ formalin at $20 \mathrm{~cm}$ water pressure [40], and lung morphometry was evaluated as described below.

\section{Lung Morphometry}

Lungs from experiment 2 ( $n=4$ /group) were inflated and perfusion fixed with neutral phosphate-buffered $10 \%$ formalin [41]. 5 - $\mu \mathrm{m}$-thick sections were prepared from the base to apex of each lung, and sections were stained with hematoxylin and eosin. Six random fields were evaluated per slide for each variable as previously described [29] by an observer masked to slide identity. The software package MetaMorph (Universal Imaging Corporation, Downingtown, Pa., USA) interfaced with a Nikon Labophot microscope equipped with a QiCam Fast Cooled high resolution CCD camera $(1,392 \times 1,040$ pixels $=4.15 \mathrm{MB}$ TIF file per image $)$ was used for image analysis. Epithelial injury and hemorrhage were assessed at a magnification of $400 \times$ using a scale of 0 (normal) to 5 (most), based on predefined definitions (e.g., a hemorrhage score of 1 corresponds to red blood cells (RBC) in septae while a score of 2 corresponds to scattered intra-alveolar RBC (modified from Simma et al. [42]). Tissue density and mean linear intercept [43] were assessed at $100 \times$. Tissue density was the proportion of field occupied by tissue (area occupied by tissue/area occupied by lung tissue plus alveoli). The RAC, an indicator of the number of new generations of alveoli that develop between the bronchiole and the periphery of its acinus, was measured by the method of Cooney and Thurlbeck [44]. Briefly, an imaginary perpendicular line is drawn extending from a terminal bronchiole to the closest edge of the acinus, either the pleura or a lobular septum. The number of saccular wall intercepts between the origin and the pleura was the RAC. This was measured on six different $100 \times$ fields per slide, each slide consisting of a coronal section from apex to base of both lungs.

\section{Retinoid Analysis}

Plasma retinol was determined after saponification, and lung and liver REs and retinol were quantified after total lipid extraction and separation of retinol and REs by reverse-phase HPLC [29, 45] using trimethylmethoxyphenyl-retinol added as an internal standard for quantification. Unesterified retinol was typically $<5 \%$ of RE in the lungs and $<2 \%$ of RE in the liver, and was included as total $\mathrm{RE}+\mathrm{retinol} / \mathrm{g}$ tissue.

\section{Statistics}

Data are reported as the mean \pm SEM. The results were analyzed by one-way ANOVA or Student's t test when appropriate (SuperANOVA software, Abacus, Berkeley, Calif., USA). Data were subjected to $\log _{10}$ transformation prior to statistical analysis when group variances were unequal. Results with $\mathrm{p}<0.05$ were considered significant.

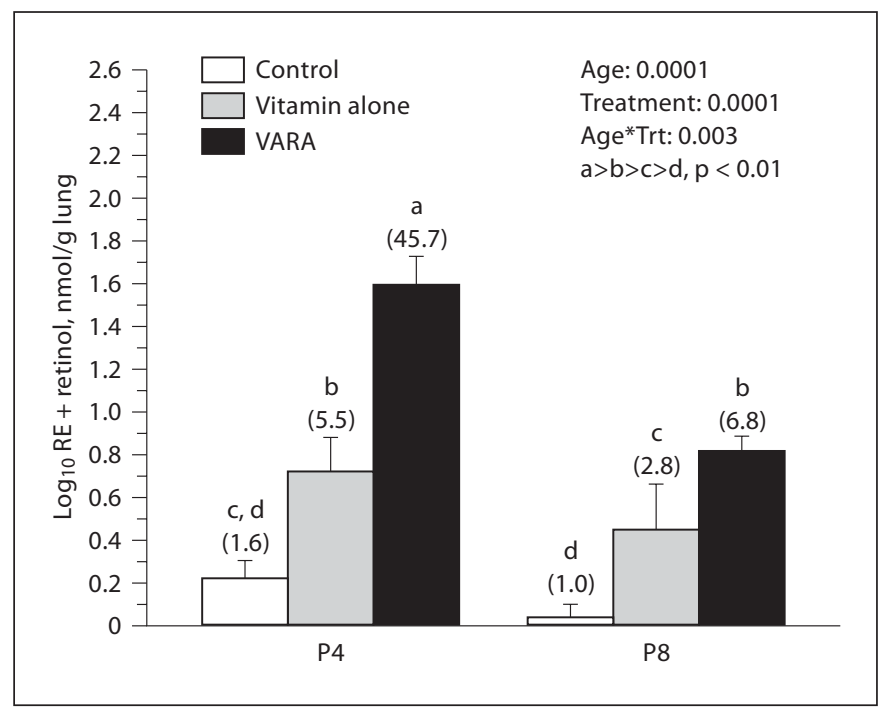

Fig. 1. Lung RE on postnatal $(\mathrm{P})$ days 4 and 8 in newborn rats treated with VARA, vitamin A or oil. Newborn rats ( $=7$ /group) were treated on days 1, 2 and 3 with oil (control), vitamin A alone, or VARA, and lung RE was determined on P4 ( $n=4$ /group) and $\mathrm{P} 8$ ( $\mathrm{n}=3$ /group). Data are the mean $\pm \mathrm{SD}$ and were analyzed by 2 -way ANOVA after $\log _{10}$ transformation (as illustrated), and the least squares means test. Values shown in parentheses are the anti-logs of the $\log _{10}$ means.

\section{Results}

\section{Retinoic Acid Combined with Vitamin A (VARA) Increases Lung RE in Newborns, which Persists after Treatment}

To determine whether the lungs of newborn rats respond to VARA, newborn rats $<24$ h old were treated daily for 3 days, beginning on P1, with VARA, vitamin A alone, or oil (normal control group). Lung RE was determined on P4 in half of the neonates, and on P8 in the remaining neonates. Lung RE on P4 was about 8 times higher in the VARA group than in the group that received an equal amount of vitamin A alone (fig. 1), while vitamin A alone increased lung RE about 3.4 times above the level in the control group on P4. After cessation of treatment, there was a net reduction in RE (expressed per gram of lung tissue) between P4 and P8. Part of this reduction was due to growth, as the average body weight increased from 9.0 to $16.5 \mathrm{~g}$ during this interval. After the last treatment with VARA or vitamin A on P3, when evaluated on P8, lung RE fell by $82 \%$ in the VARA group, and by $50 \%$ in the vitamin A group. However, despite this reduction, the lung RE concentration on P8 was still sig- 


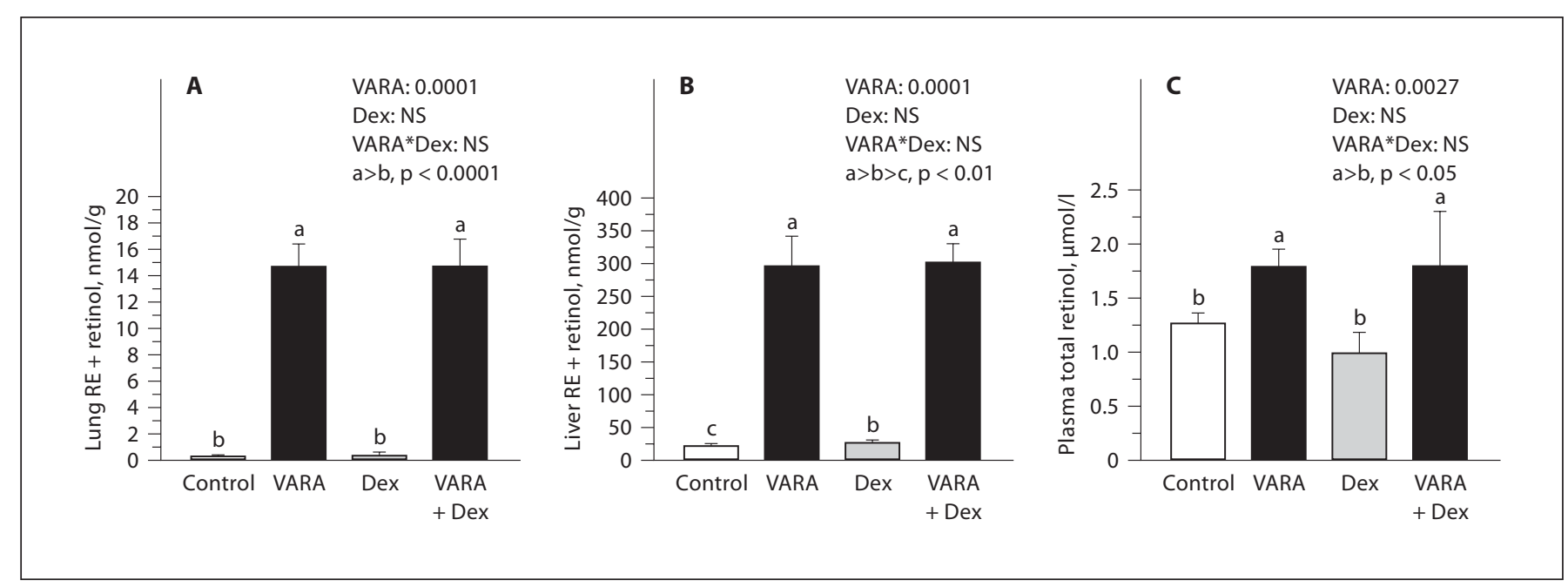

Fig. 2. Lung and liver retinyl ester in 8-day-old rats treated with oil (control), VARA, dexamethasone (Dex), or Dex and VARA. A Lung RE + retinol concentration. B Liver RE + retinol concentration. C Plasma total retinol. For each treatment, $\mathrm{n}=3$ pools/group were analyzed by HPLC; each pool contained equal portions of tissue from 2 identically treated neonates. The results were analyzed by two-way ANOVA; different letters above groups indicate significant differences by the least squares means test.

Table 1. Growth characteristics and lung morphometry in neonatal rats treated on P5-P7 with Dex, VARA, and the combination

\begin{tabular}{lccccc}
\hline & Control & Dex & VARA & Dex/VARA & $\begin{array}{c}\text { ANOVA } \\
\text { p value }\end{array}$ \\
\hline Growth during treatment (P5-P8), g & $4.6 \pm 0.4^{\mathrm{a}}$ & $2.8 \pm 0.2^{\mathrm{b}}$ & $4.5 \pm 0.2^{\mathrm{a}}$ & $3.0 \pm 0.6^{\mathrm{b}}$ & $<0.0001$ \\
Body weight (P14), g & $13.9 \pm 0.2$ & $13.5 \pm 1.6$ & $13.9 \pm 1.4$ & $15.0 \pm 1.2$ & 0.95 \\
Tissue density, \% of area occupied & $29.0 \pm 5.6^{\mathrm{a}, \mathrm{b}}$ & $35.5 \pm 2.4^{\mathrm{a}}$ & $31.8 \pm 4.0^{\mathrm{a}, \mathrm{b}}$ & $26.5 \pm 4.8^{\mathrm{b}}$ & 0.066 \\
Radial alveolar counts, number of septae & $5.6 \pm 1.2$ & $5.4 \pm 0.4$ & $5.9 \pm 1.2$ & $4.6 \pm 0.6$ & 0.25 \\
\hline
\end{tabular}

Lungs were perfusion-fixed and examined on day P14. Mean \pm SD ( $n=4 /$ group).

$\mathrm{a}>\mathrm{b}$ The mean of the group marked 'a' is greater than that of the group marked ' $b$ '. $p<0.001$ by least squares means test.

nificantly greater in neonates previously treated with VARA (VARA > vitamin A > control, $\mathrm{p}<0.01$ ).

\section{Dex Reduces Growth, but Does Not Antagonize the Lung RE Response to VARA}

To determine if VARA is effective in increasing lung $\mathrm{RE}$ during co-treatment with Dex, neonates received either oil (control) or VARA, both without and with Dex, on P5-7. Table 1 shows growth during and following treatment with Dex, and lung histology parameters measured on P14, seven days after the last treatments with Dex and VARA. During treatment, Dex reduced growth by approximately $30 \%$, as expected from several previous reports [38, 46-48]. The slowing of growth by Dex was significant within the first day of treatment $(\mathrm{p}<0.01$, data not shown). None of the treatments resulted in significant lung injury (mean hemorrhage score was $<0.5$, and epithelial injury score was $<0.7$, on a scale of $0-5$, for all groups). Tissue density was lower in the Dex-VARA group than the Dex only group. Radial alveolar counts did not differ by treatment.

Lung RE was significantly increased in neonates treated with VARA alone $(p<0.0001)$. Co-treatment with Dex did not affect the response to VARA (fig. 2A), and Dex alone had no significant effect on lung RE as compared to the control group without Dex. 
VARA significantly increased liver RE $(\mathrm{p}<0.01)$. Concomitant treatment with Dex did not affect the response to VARA (fig. 2B), while Dex alone caused a slight increase, compared to the control group.

Plasma total retinol (fig. 2C), determined on P8, was somewhat higher in VARA-treated neonates $(\mathrm{p}<0.0001)$, although values in all groups were still in the normal range for rats. Plasma retinol was moderately but not significantly reduced by Dex; however, Dex did not alter plasma retinol response to VARA.

\section{Discussion}

Vitamin A in the Newborn Period - Rationale

Several epidemiological and clinical studies have shown that a nutritional deficiency of vitamin A impairs the response to infectious diseases and increases the risk of mortality [for review, see 49,50], whereas vitamin A supplementation has successfully reduced child mortality in populations at risk of vitamin A deficiency [51]. Mortality was reduced by 64 and 22\% in Indonesian and Indian newborns, respectively, who received 50,000 IU of vitamin A (equal to $15 \mathrm{mg}$ retinol) immediately after birth $[35,36]$. Strategies to improve vitamin A status in the postnatal period are also of clinical interest as vitamin A has been shown to improve the clinical outcome of extremely low birth weight infants hospitalized for treatment of respiratory distress syndrome [7]. In such settings, hospitalized infants often receive multiple treatments, such as corticosteroids or supplemental oxygen, and therefore it is important to understand the interaction of vitamin A with these treatments.

\section{VARA Increases Lung RE in Newborn Rats More}

Effectively than Vitamin A

In the present studies we tested a novel preparation, VARA, which is a nutrient-metabolite combination of vitamin A and RA at a 10:1 ratio, for its ability to increase the RE contents of the lungs of newborn rats. VARA, compared to a standard dose of vitamin A, was more effective in newborn rats treated on P1-P3, as lung RE on $\mathrm{P} 4$ was nearly 8 -fold higher in VARA than in vitamin A neonates. In this period the lungs of newborn rats are in the saccular stage of lung development, similar to that of 24-38 weeks gestational age in humans [30]. The robust increase in lung RE in VARA-treated neonatal rats suggests that this combination dose might be effective in selectively increasing the uptake of retinol into the lungs of premature infants. Because VARA and vitamin A both increased liver RE, and liver vitamin A storage is widely considered as the best indicator, or 'gold standard', of whole-body vitamin A status $[52,53]$, these treatments should be equally effective in improving the overall vitamin A status in neonates, and both would be expected to protect the neonate against the development of vitamin A deficiency. After the last treatment of newborn rats with VARA on P3, the lung RE concentration declined, indicating that newly deposited lung RE can be mobilized. Despite this reduction, RE was still $>2$ fold higher on P8 in VARA versus vitamin A neonates. The continued elevation of RE after treatment suggests that it might be possible to provide VARA at less frequent intervals and still maintain elevated tissue reserves over several days or longer. Tissue RE storage is essential for the functions of vitamin $A$ because $R E$ is the major form of vitamin $A$ in most tissues and is readily mobilized through hydrolysis to retinol, the immediate substrate for oxidation to retinal acid and RA, the two principal active metabolites of vitamin A [for review see, 22, 54]. It will be important in the future to determine the biochemical fate of VARAinduced lung RE stores, and to understand whether increasing lung RE contents early in life, as in our newborn rat study, has any physiological benefit regarding postnatal lung maturation.

\section{VARA Is Not Antagonized by Dex}

Our second study showed that VARA, when given concurrently with Dex, was still effective in increasing lung RE storage. Dex was observed to reduce growth during the period in which it was administered (P5-P7), but body weights on P14 were not different. While previous studies with longer courses of glucocorticoids have shown detrimental effects on alveolarization [31, 32], neonatal rats treated with a short course of VARA, Dex or both combined showed no unusual changes in several indicators of lung injury in our study. These findings in the neonatal rat model may be clinically relevant, especially as neonatologists currently avoid prolonged courses and prefer much shorter courses of steroids.

It has previously been reported that Dex depletes the lungs and liver of vitamin A in vitamin-A-adequate (nonsupplemented) neonatal rats [55]. However, Dex did not antagonize the effect of VARA given as an oral supplement. It is possible that the marked increase in RE due to VARA overwhelmed a smaller reduction in RE due to Dex. In most previous studies of Dex-treated postnatal rats, Dex has been administered for a longer time, e.g., $\mathrm{P} 3-\mathrm{P} 13$, and reduced alveolarization has been documented $[38,46,47]$. However, treatment with RA after cessa- 
tion of Dex partially rescued septation by increasing the number of alveoli in postnatal rats [56]. Srinivasan et al. [57] reported that Dex decreased and all-trans-RA increased lung alveolar formation in P4-P13 rats, but RA did not prevent Dex-induced changes in lung function. Thus, the interactions of retinoids and Dex are complex, including the effects of Dex on the concentrations of nuclear retinoid receptors [46] and cellular retinoid-binding proteins [33]. The effects of both retinoids and Dex are likely to depend on the time during development in which they are administered. Now that the present study has shown that Dex does not abrogate the effect of VARA in augmenting lung RE formation, it will be worthwhile to conduct a more detailed study of Dex + VARA-treated neonates to determine if VARA helps to ameliorate Dexinduced lung injury during treatment and in the period of catch-up growth.

\section{Conclusions}

VARA increased lung RE content 8-fold more effectively than vitamin A in newborn and 1-week-old neonatal rats, and the increase in lung RE due to VARA was not attenuated by Dex. This novel nutrient-metabolite com- bination may be useful and potentially more effective than vitamin A alone in delivering retinol to the lungs in the perinatal period. The effectiveness of VARA in increasing RE in newborn rat lungs in the late saccular stage suggests that VARA may have potential in premature infants, while the effectiveness of VARA in the presence of Dex suggests that co-treatment with glucocorticoid therapy would not interfere with the accumulation of RE in the lungs. Further studies of the physiological effects of VARA in neonates are warranted. The synergistic effect of vitamin A and retinoic acid that we have demonstrated in the newborn rat model is of possible therapeutic significance. Pilot clinical trials are needed to determine optimal dosage, followed by a larger multi-center randomized controlled trial to prove efficacy in reducing $\mathrm{BPD}$ in the human preterm neonate.

\section{Acknowledgement}

This work was supported in part by NIH R01 CA-90214 (A.C.R.), K08 HD-046513 (N.A.), C06 RR 15490 (N.A.), and funding from the Children's Center Research Initiative (N.A.) and Dorothy Foehr Huck funds (A.C.R.). The authors are grateful to Dr. Nan-qian Li for assistance with tissue analysis.

\section{References}

1 Short EJ, Klein NK, Lewis BA, Fulton S, Eisengart S, Kercsmar C, Baley J, Singer LT: Cognitive and academic consequences of bronchopulmonary dysplasia and very low birth weight: 8 -year-old outcomes. Pediatrics 2003; 112:e359.

$\checkmark 2$ Ambalavanan N, Tyson JE, Kennedy KA, Hansen NI, Vohr BR, Wright LL, Carlo WA; National Institute of Child Health and $\mathrm{Hu}-$ man Development Neonatal Research Network: Vitamin A supplementation for extremely low birth weight infants: outcome at 18 to 22 months. Pediatrics 2005; 115:e249e254.

-3 Schmidt B, Asztalos EV, Roberts RS, Robertson CM, Sauve RS, Whitfield MF: Impact of bronchopulmonary dysplasia, brain injury, and severe retinopathy on the outcome of extremely low-birth-weight infants at 18 months: results from the trial of indomethacin prophylaxis in preterms. JAMA 2003; 289:1124-1129.

4 Hustead VA, Gutcher GR, Anderson SA, Zachman RD: Relationship of vitamin A (retinol) status to lung disease in the preterm infant. J Pediatr 1984;105:610-615.
5 Shenai JP, Kennedy KA, Chytil F, Stahlman MT: Clinical trial of vitamin A supplementation in infants susceptible to bronchopulmonary dysplasia. J Pediatr 1987;111:269-277.

6 Shenai JP, Rush MG, Stahlman MT, Chytil F: Vitamin A supplementation and bronchopulmonary dysplasia - revisited. J Pediatr 1992;121:399-401.

>7 Tyson JE, Wright LL, Oh W, Kennedy KA, Mele L, Ehrenkranz RA, Stoll BJ, Lemons JA, Stevenson DK, Bauer CR, Korones SB, Fanaroff AA: Vitamin A supplementation for extremely-low-birth-weight infants. National Institute of Child Health and Human Development Neonatal Research Network. N Engl J Med 1999;340:1962-1968.

8 Baybutt RC, Hu L, Molteni A: Vitamin A deficiency injures lung and liver parenchyma and impairs function of rat type II pneumocytes. J Nutr 2000;130:1159-1165.

9 McGowan SE, Doro MM, Jackson SK: Endogenous retinoids increase perinatal elastin gene expression in rat lung fibroblasts and fetal explants. Am J Physiol 1997;273: L410-L416.
10 Bland RD, Albertine KH, Pierce RA, Starcher BC, Carlton DP: Impaired alveolar development and abnormal lung elastin in preterm lambs with chronic lung injury: potential benefits of retinol treatment. Biol Neonate 2003;84:101-102.

11 Takatsuka J, Takahashi N, de Luca LM: Retinoic acid metabolism and inhibition of cell proliferation: an unexpected liaison. Cancer Res 1996;56:675-678.

12 Clarke N, Germain P, Altucci L, Gronemeyer $\mathrm{H}$ : Retinoids: potential in cancer prevention and therapy. Expert Rev Mol Med 2004;6: $1-23$.

13 Warburton D, Schwarz M, Tefft D, FloresDelgado G, Anderson KD, Cardoso WV: The molecular basis of lung morphogenesis. Mech Dev 2000;92:55-81.

14 McGowan SE: Contributions of retinoids to the generation and repair of the pulmonary alveolus. Chest 2002;121(suppl):206S-208S.

15 Chinoy MR: Lung growth and development. Front Biosci 2003;8:D392-D415.

16 Chytil F: Retinoids in lung development. FASEB J 1996;10:986-992. 
17 Zachman RD, Grummer MA: Retinoids and lung development; in Zachman RD, Grummer MA (eds): Contemporary Endocrinology. Endocrinology of the Lung: Development and surfactant synthesis. Totowa, Humana Press, 2000, pp 161-179.

-18 Pierce RA, Shipley JM: Retinoid-enhanced alveolization. Identifying relevant downstream targets. Am J Respir Cell Mol Biol 2000;23:137-141.

19 Belloni PN, Garvin L, Mao CP, Bailey-Healy I, Leaffer D: Effects of all-trans-retinoic acid in promoting alveolar repair. Chest 2000; 117(suppl 1):235S-241S.

20 Massaro D, Massaro GD: Invited review: pulmonary alveoli: formation, the 'call for oxygen', and other regulators. Am J Physiol Lung Cell Mol Physiol 2002;282:L345L358.

21 Maden M, Hind M: Retinoic acid in alveolar development, maintenance and regeneration. Philos Trans R Soc Lond B Biol Sci 2004;359:799-808.

22 Napoli JL: Enzymology and biogenesis of retinoic acid; in Livrea MA (ed): Vitamin A and Retinoids: An Update of Biological Aspects and Clinical Applications. Basel, Birkhäuser, 2000, pp 17-27.

23 Ross AC, Harrison EH: Vitamin A and carotenoids; in McCormick DB, Rucker RR, Suttie JW, Zempleni J (eds): Handbook of Vitamins. Boca Raton, CRC Press, 2006, pp 5-28.

24 Shenai JP, Chytil F, Stahlman MT: Liver vitamin A reserves of very low birth weight neonates. Pediatr Res 1985;19:892-893.

-25 Shenai JP, Rush MG, Stahlman MT, Chytil F: Plasma retinol-binding protein response to vitamin A administration in infants susceptible to bronchopulmonary dysplasia. J Pediatr 1990;116:607-614.

26 Zachman RD, Samuels DP, Brand JM, Winston JF, Pi JT: Use of the intramuscular relative-dose-response test to predict bronchopulmonary dysplasia in premature infants. Am J Clin Nutr 1996;63:123-129.

-27 Shenai JP, Chytil F: Vitamin A storage in lungs during perinatal development in the rat. Biol Neonate 1990;57:126-132.

28 Shenai JP, Chytil F: Effect of maternal vitamin-A administration on fetal lung vitaminA stores in the perinatal rat. Biol Neonate 1990b;58:318-325.

-29 Ross AC, Ambalavanan N, Zolfaghari R, Li NQ: Vitamin A combined with retinoic acid increases retinol uptake and lung retinyl ester formation in neonatal rats. J Lipid Res 2006;47:1844-1851.

30 Roth-Kleiner M, Post M: Similarities and dissimilarities of branching and septation during lung development. Pediatr Pulmonol 2005;40:113-134.
1 Grier DG, Halliday HL: Management of bronchopulmonary dysplasia in infants: guidelines for corticosteroid use. Drugs 2005;65:15-29.

32 Purdy IB: Perinatal corticosteroids: a review of the research. Part II: Postnatal administration. Neonatal Netw 2004;23:13-25.

33 Whitney D, Massaro GD, Massaro D, Clerch LB: Gene expression of cellular retinoidbinding proteins: Modulation by retinoic acid and dexamethasone in postnatal rat lung. Pediatr Res 1999;45:2-7.

34 Grummer MA, Zachman RD: Postnatal rat lung retinoic acid receptor (RAR) mRNA expression and effects of dexamethasone on RAR $\beta$ mRNA. Pediatr Pulmonol 1995;20: 234-240.

-35 Humphrey JH, Agoestina T, Wu L, Usman A, Nurachim M, Subardja D, Hidayat S, Tielsch J, West KP Jr, Sommer A: Impact of neonatal vitamin A supplementation on infant morbidity and mortality. J Pediatr 1996;128: 489-496.

36 Rahmathullah L, Tielsch JM, Thulasiraj RD, Katz J, Coles C, Devi S, John R, Prakash K, Sadanand AV, Edwin N, Kamaraj C: Impact of supplementing newborn infants with vitamin A on early infant mortality: community based randomised trial in southern India. BMJ 2003;327:254-260.

37 Massaro GD, Massaro D: Postnatal treatment with retinoic acid increases the number of pulmonary alveoli in rats. Am J Physiol Lung Cell Mol Physiol 1996;270: L305-L310.

38 Massaro D, Massaro GD: Dexamethasone accelerates postnatal alveolar wall thinning and alters wall composition. Am J Physiol Lung Cell Mol Physiol 1986;251:R218R224.

-39 Dawson HD, Li NQ, DeCicco KL, Nibert JA, Ross AC: Chronic marginal vitamin A status reduces natural killer cell number and function in aging Lewis rats. J Nutr 1999;129: 1510-1517.

40 Bruce MC, Bruce EN, Janiga K, Chetty A: Hyperoxic exposure of developing rat lung decreases tropoelastin mRNA levels that rebound postexposure. Am J Physiol Lung Cell Mol Physiol 1993;265:L293-L300.

41 Auten RL, Whorton MH, Mason SN: Blocking neutrophil influx reduces DNA damage in hyperoxia-exposed newborn rat lung. Am J Resp Cell Mol Biol 2002;26:391-397.

42 Simma B, Luz G, Trawoger R, Hormann C, Klima G, Kreczy A, Baum M: Comparison of different modes of high-frequency ventilation in surfactant-deficient rabbits. Pediatr Pulmonol 1996;22:263-270.

43 McGowan S, Jackson SK, Jenkins-Moore M, Dai HH, Chambon P, Snyder JM: Mice bearing deletions of retinoic acid receptors demonstrate reduced lung elastin and alveolar numbers. Am J Respir Cell Mol Biol 2000;23: 162-167.
44 Cooney TP, Thurlbeck WM: The radial alveolar count method of Emery and Mithal: a reappraisal 1 - postnatal lung growth. Thorax 1982;37:572-579.

45 Zachman RD, Kakkad B, Chytil F: Perinatal rat lung retinol (vitamin A) and retinyl palmitate. Pediatr Res 1984;18:1297-1299.

46 McMenamy KR, Anderson MJ, Zachman RD: Efffect of dexamethasone and oxygen exposure on neonatal rat lung retinoic acid receptor proteins. Pediatr Pulmonol 1994; 18:232-238.

47 Grummer MA, Zachman RD: Retinoic acid and dexamethasone affect RAR-beta and surfactant protein C mRNA in the MLE lung cell line. Am J Physiol Lung Cell Mol Physiol 1998;274:L1-L7.

48 Okajima S, Matsuda T, Cho K, Matsumoto Y, Kobayashi Y, Fujimoto S: Antenatal dexamethasone administration impairs normal postnatal lung growth in rats. Pediatr Res 2001;49:777-781.

49 Villamor E, Fawzi WW: Effects of vitamin A supplementation on immune responses and correlation with clinical outcomes. Clin Microbiol Rev 2005; 18:446-464.

50 Stephensen CB: Vitamin A, infection, and immune function. Annu Rev Nutr 2001;21: 167-192.

-51 Ching P, Birmingham M, Goodman T, Sutter R, Loevinsohn B: Childhood mortality impact and costs of integrating vitamin $\mathrm{A}$ supplementation into immunization campaigns. Am J Public Health 2000;90:15261529.

52 Ross AC, Zolfaghari R: Regulation of hepatic retinol metabolism: perspectives from studies on vitamin A status. J Nutr 2004;134: 269S-275S.

53 Valentine AR, Tanumihardjo SA: One-time vitamin A supplementation of lactating sows enhances hepatic retinol in their offspring independent of dose size. Am J Clin Nutr 2005;81:427-433.

54 Ross AC, Zolfaghari R, Weisz J: Vitamin A: recent advances in the biotransformation, transport, and metabolism of retinoids. Curr Opin Gastroenterol 2001;17:184-192.

55 Georgieff MK, Radmer WJ, Sowell AL, Yeager PR, Blaner WS, Gunter EW, Johnson DE: The effect of glucocorticosteroids on serum, liver, and lung vitamin A and retinyl ester concentrations. J Pediatr Gastroenterol Nutr 1991;382:376-382.

56 Massaro GD, Massaro D: Retinoic acid treatment partially rescues failed septation in rats and in mice. Am J Physiol Lung Cell Mol Physiol 2000;278:L955-L960.

57 Srinivasan G, Bruce EN, Houtz PK, Bruce MC: Dexamethasone-induced changes in lung function are not prevented by concomitant treatment with retinoic acid. Am J Physiol Lung Cell Mol Physiol 2002;283: L275-L287. 